\title{
Diurnal variations of aerosol optical properties in the North China Plain and their influences on the estimates of direct aerosol radiative effect
}

\author{
Y. Kuang ${ }^{1}$, C. S. Zhao ${ }^{1}$, J. C. Tao ${ }^{1}$, and N. Ma ${ }^{1,2}$ \\ ${ }^{1}$ Department of Atmospheric and Oceanic Sciences, School of Physics, Peking University, Beijing, China \\ ${ }^{2}$ Leibniz Institute for Tropospheric Research, Leipzig, Germany
}

Correspondence to: C. S. Zhao (zcs@pku.edu.cn)

Received: 24 November 2014 - Published in Atmos. Chem. Phys. Discuss.: 7 January 2015

Revised: 29 April 2015 - Accepted: 4 May 2015 - Published: 26 May 2015

\begin{abstract}
In this paper, the diurnal variations of aerosol optical properties and their influences on the estimation of daily average direct aerosol radiative effect (DARE) in the North China Plain (NCP) are investigated based on in situ measurements from Haze in China campaign. For ambient aerosol, the diurnal patterns of single scattering albedo (SSA) and asymmetry factor $(g)$ in the NCP are both highest at dawn and lowest in the late afternoon, and quite different from those of dry-state aerosol. The relative humidity $(\mathrm{RH})$ is the dominant factor which determines the diurnal pattern of SSA and $g$ for ambient aerosol. Basing on the calculated SSA and $g$, several cases are designed to investigate the impacts of the diurnal changes of aerosol optical properties on DARE. The results demonstrate that the diurnal changes of SSA and $g$ in the NCP have significant influences on the estimation of DARE at the top of the atmosphere (TOA). If the full temporal coverage of aerosol optical depth (AOD), SSA and $g$ are available, an accurate estimation of daily average DARE can be achieved by using the daily averages of AOD, SSA and $g$. However, due to the lack of full temporal coverage data sets of SSA and $g$, their daily averages are usually not available. Basing on the results of designed cases, if the RH plays a dominant role in the diurnal variations of SSA and $g$, we suggest that using both SSA and $g$ averaged over early morning and late afternoon as inputs for radiative transfer model to improve the accurate estimation of DARE. If the temporal samplings of SSA or $g$ are too few to adopt this method, either averaged over early morning or late afternoon of both SSA and $g$ can be used to improve the estimation of DARE at the TOA.
\end{abstract}

\section{Introduction}

The direct effect of atmospheric aerosol on the radiation budget of earth is commonly described by direct aerosol radiative effect (DARE). DARE can be estimated from global aerosol models directly (Myhre et al., 2013), observations (Bellouin et al., 2005, 2008), or a combination of these two methods (Su et al., 2013). Most observation-based methods use satellite data of aerosol optical depth (AOD) in combination with aerosol optical properties retrieved from ground-based sun photometers from Aerosol Robotic Network (AERONET) (Holben et al., 1998), where the single scattering albedo (SSA) and asymmetry factor $(g)$ are usually held constant (Myhre, 2009; Bellouin et al., 2013). However, variations of the aerosol optical properties, including AOD, SSA and $g$, are important information for the estimates of daily average DARE, and thus the monthly and annually averaged DARE as well.

The spatial and temporal distributions of aerosol optical properties are sampled either from space or at the earth's surface. For instance, the Moderate Resolution Imaging Spectroradiometer (MODIS) onboard Terra and Aqua pass over the equator in the morning and afternoon, respectively. Thus, temporal coverage of aerosol optical properties retrieved from satellites is limited to specific time periods. In addition, the widely used ground-based AERONET retrievals provide AOD at relatively higher temporal resolution, but the intensive optical properties (SSA and $g$ ) retrieved from AERONET measurements are typically limited to shorter time periods in the morning and afternoon when the solar zenith angle $(\mathrm{SZA})$ is quite large $\left(50^{\circ} \leq \mathrm{SZA} \leq 70^{\circ}\right)$ (Holben 
et al., 2006; Dubovik et al., 2000; Kassianov et al., 2013). Although the study of Kaufman et al. (2000) revealed that Terra and Aqua measurements can represent the annual average value within $2 \%$ error, still, the incomplete temporal samplings of aerosol optical properties may be incapable of faithfully reproducing the diurnal variations of aerosol optical properties, especially for SSA and $g$. Therefore, the aerosol optical properties are usually assumed to be constants (Sena et al., 2013; Myhre, 2009) or with negligible variability through the day of interest (Remer and Kaufman, 2006). So far, significant diurnal changes of AOD have been frequently observed in many polluted regions around the world (Zhang et al., 2012; Mazzola et al., 2010; Smirnov et al., 2002), but diurnal changes of SSA and $g$ for ambient aerosol are rarely investigated.

The diurnal variations of these optical properties have rarely been taken into account in the measurement-based estimates of DARE. Arola et al. (2013) exploited data from a large number of AERONET sites, and assessed the influence of diurnal AOD variability on the estimates of daily average DARE at the top of atmosphere (TOA). Their results demonstrated that, for individual sites, there can be significant biases in the estimates of DARE due to the diurnal AOD variability. However, if averaged over all AERONET sites, the influence of diurnal changes of AOD on the daily averaged DARE is rather small, the relative differences are essentially within $\pm 10 \%$, and the major part is centered within $\pm 5 \%$, even for cases in which AOD is taken either from Terra or Aqua overpass time. But the diurnal changes of SSA and $g$ were not considered, and seasonal averages were used in this research. Kassianov et al. (2013) also assessed the impacts of diurnal variations of aerosol optical properties on the estimates of daily averaged DARE. Their results demonstrated that even in the presence of strong diurnal changes of AOD, an accurate prediction of daily average DARE requires only daily averaged aerosol optical properties. Nevertheless, the diurnal variations of SSA and $g$ were not also considered in this research due to their small ranges.

With the rapid growth of population and economy in China, emissions of anthropogenic pollutants have increased dramatically in recent decades, and China is suffering from very serious air pollution. The high aerosol loading in the North China Plain (NCP) is an important factor which affects regional climate change due to their potential radiative effects (Zhao et al., 2006), an accurate estimation of DARE in this region is therefore important. The published results from Haze in China (HaChi) campaign demonstrated that many aerosol physical and chemical properties have significant diurnal variations (Ma et al., 2011; Liu et al., 2011; Ran et al., 2011; Xu et al., 2011), which are different from the results for other regions around the world. Some scientific questions regarding the diurnal variation of aerosol optical properties in the NCP arose: (1) what are the characterizations of diurnal variations of aerosol optical properties in the NCP, such as SSA and $g$ ? (2) Do the diurnal variations of aerosol optical properties have significant impacts on the estimation of daily average DARE in the NCP?

In this paper, the diurnal variations of SSA and $g$ at ambient and dry conditions are presented at a regional background site in the NCP. The calculated SSA and $g$ are used to investigate the influences of their diurnal variability on the estimates of daily average DARE at the TOA and surface. This is the first time, in the NCP, that the diurnal cycles of SSA and $g$ are both taken into account in the prediction of daily average DARE. This is particularly important for studying the direct aerosol effect in the NCP, where absorbing and scattering aerosols may contribute significantly to the climate change of the earth system (Chung et al., 2005; Bond et al., 2013).

In Sect. 2, the site information and related instruments are introduced. Data and methods used in this research are described in Sect. 3. Section 4 presents the calculated diurnal variations of aerosol optical properties and their influences on the estimates of daily average DARE. Finally, conclusions are reached in Sect. 5.

\section{Site description and instruments}

In this study, we use the data set from the HaChi project which is conducted jointly by Peking University, China and Leibniz-Institute for Tropospheric Research, Germany at Wuqing $\left(39^{\circ} 23^{\prime} \mathrm{N}, 117^{\circ} 01^{\prime} \mathrm{E}\right)$. This observation campaign lasted for about 1 month from 12 July 2009 to $14 \mathrm{Au}$ gust 2009. The Wuqing site is located at the northern part of the NCP, between two megacities, Beijing and Tianjin. The distance between Wuqing and downtown Beijing is about $80 \mathrm{~km}$, and is about $30 \mathrm{~km}$ between Wuqing and downtown Tianjin. Wuqing site is mainly surrounded by farmland and residential areas. The emission sources nearby are similar to those in most parts of the northern NCP. Hence, as a regional background site, the observational results in Wuqing can, to a large extent, represent the background aerosol properties in the northern NCP.

The particle number size distribution (PNSD) at dry state ranging from $3 \mathrm{~nm}$ to $10 \mu \mathrm{m}$ was observed jointly by an Aerodynamic Particle Sizer (APS, TSI Inc., Model 3321) and a Twin Differential Mobility Particle Sizer (TDMPS, LeibnizInstitute for Tropospheric Research (IfT), Germany; Birmili et al., 1999) with a temporal resolution of $10 \mathrm{~min}$, and the relative humidity $(\mathrm{RH})$ of sampling air is controlled at lower than $30 \%$. The absorption coefficient at $637 \mathrm{~nm}$ was measured using a Multi-angle Absorption Photometer (MAAP Model 5012, Thermo, Inc., Waltham, MA USA) with a temporal resolution of $1 \mathrm{~min}$, and further transformed into black carbon (BC) mass concentrations with a constant mass absorption efficiency (MAE) of $6.6 \mathrm{~m}^{2} \mathrm{~g}^{-1}$. The growth factors of aerosols at RH spanning $0-98 \%$ are obtained from the observation of the High Humidity Tandem Differential Mobility Analyzer (HH-TDMA, Leibniz-Institute for Tropospheric Research (IfT), Germany; Hennig et al., 2005). The 
HH-TDMA measured the growth factor at four selected particle diameters $(50,100,200$ and $250 \mathrm{~nm})$ and three RH conditions $(90,95$ and $98.5 \%)$. For detailed information of the measurements, please refer to Ma et al. (2011) and Liu et al. (2011).

Furthermore, ambient RH with 1 min temporal resolution was measured by an automatic weather station (AWS). Other observational data (e.g., scattering coefficient at wavelengths of 450,550 and $700 \mathrm{~nm}$ ) used to retrieve the mixing state of light absorbing aerosol are in another study (Ma et al., 2012).

\section{Data and methods}

\subsection{Calculation of aerosol optical properties}

The estimation of DARE requires some aerosol optical properties, such as AOD, SSA and phase function, however, $g$ usually used as an approximation of the phase function in the realistic calculation of DARE, although this approximation will introduce errors (Boucher, 1998). In this study, the AOD data from AERONET measurements at Xianghe site were used (Holben et al., 2006). Similar with Wuqing, Xianghe is also a background site of the NCP, the distance between them is about $40 \mathrm{~km}$. SSA and $g$ were calculated using the measurements from HaChi campaign, considering both the mixing state of light absorbing carbonaceous (LAC) aerosol and the hygroscopic growth.

Ma et al. (2012) proposed a new method to retrieve the mixing state of LAC. In this method, aerosol chemical components are separated into two classes based on their refractive indices: the LAC and the less absorbent components (inorganic salts and acids, and most of the organic compounds). And dry-state aerosols are classified into two assumed types: externally mixed LAC and core-shell mixed LAC coated by less absorbent components. The mixing state of ambient aerosol is described by the mass ratio of externally mixed LAC to total LAC:

$r_{\text {ext-LAC }}=M_{\text {ext-LAC }} / M_{\mathrm{LAC}}$,

where $M_{\text {ext-LAC }}$ is the mass concentration of externally mixed LAC, and $M_{\mathrm{LAC}}$ is the total mass concentration of LAC measured by MAAP. According to this assumption, measured PNSD of aerosol particles is a superposition of the PNSD of externally mixed LAC and the PNSD of core-shell mixed particles:

$$
N\left(\log D_{\mathrm{p}}\right)=N\left(\log D_{\mathrm{p}}\right)_{\text {ext-LAC }}+N\left(\log D_{\mathrm{p}}\right)_{\text {core-shell }},
$$

where $N\left(\log D_{\mathrm{p}}\right)$ is the PNSD measured by TDMPS and APS, $N\left(\log D_{\mathrm{p}}\right)_{\text {ext-LAC }}$ and $N\left(\log D_{\mathrm{p}}\right)_{\text {core-shell }}$ are the PNSDs of the externally mixed LAC and the core-shell mixed particles, respectively. With the mixing state retrieved by Ma et al. (2012), $N\left(\log D_{\mathrm{p}}\right)_{\text {ext-LAC }}$ can be derived using the following equation:

$$
N\left(\log D_{\mathrm{p}}\right)_{\text {ext-LAC }}=N\left(\log D_{\mathrm{p}}\right) \cdot r_{\mathrm{ext}-\mathrm{LAC}} \cdot f_{\mathrm{LAC}},
$$

where $f_{\mathrm{LAC}}$ is the volume fraction of LAC, which can be calculated as follows:

$$
f_{\mathrm{LAC}}=\frac{M_{\mathrm{LAC}}}{\rho_{\mathrm{LAC}} \cdot \sum_{D_{\mathrm{p}}}\left(N\left(\log D_{\mathrm{p}}\right) \cdot\left(\frac{\pi}{6} \cdot D_{\mathrm{p}}^{3}\right)\right)},
$$

where $\rho_{\text {LAC }}$ is the density of LAC, which is assumed to be $1.5 \mathrm{~g} \mathrm{~cm}^{-3}$ (Ma et al., 2012). Details about the method of retrieving the mixing state of LAC in the NCP can be found in Ma et al. (2012).

To account for the hygroscopic growth of aerosol particles, we define the growth factor as follows:

$g\left(D_{\mathrm{p}, \mathrm{dry}}, \mathrm{RH}\right)=D_{\mathrm{p}}(\mathrm{RH}) / D_{\mathrm{p}, \mathrm{dry}}$,

where $D_{\mathrm{p} \text {,dry }}$ and $D_{\mathrm{p}}(\mathrm{RH})$ is the diameter of particle at drystate and specific RH, respectively. The externally mixed LAC is assumed to be completely hydrophobic (Bond et al., 2013) and does not grow with the increasing RH. The sizeresolved hygroscopic growth factor of core-shell mixed particles are calculated using the $\kappa$ theory (Petters and Kreidenweis, 2007) to get the PNSD at ambient conditions:

$\mathrm{RH}=\frac{g^{3}-1}{g^{3}-(1-\kappa)} \cdot \exp \left(\frac{4 \sigma_{\mathrm{s} / \mathrm{a}} \cdot M_{\mathrm{water}}}{R \cdot T \cdot D_{\mathrm{p}} \cdot g \cdot \rho_{\mathrm{w}}}\right)$,

where $\sigma_{\mathrm{s} / \mathrm{a}}$ is the surface tension of solution/air interface, its value is set to be $0.072 \mathrm{~J} \mathrm{~m}^{-2}$ (Petters and Kreidenweis, 2007), $T$ is the temperature, $M_{\text {water }}$ is the molecular weight of water, and $R$ is the universal gas constant, $\rho_{\mathrm{w}}$ is the density of water, and $\kappa$ is the hygroscopicity parameter which determines the hygroscopic ability of aerosols. By solving Eq. (6), $g\left(D_{\mathrm{p}, \text { dry }}, \mathrm{RH}\right)$ at different $\mathrm{RH}$ and $D_{\mathrm{p}}$ can be obtained, and the size-resolved $\kappa$ is also required. However, up to now, no instruments are valid to provide the size-resolved $\kappa$ which have covered the full aerosol particle size range. And the method used in Chen et al. (2012) to derive the size-resolved $\kappa$ is used in this research. The $\kappa$ value of one aerosol particle is mainly related to its chemical composition (Liu et al., 2014), and the aerosol particles which have similar chemical components usually come from the similar sources and experienced similar aging processes. Therefore, in this method, first, the measured PNSD at dry state are fitted with four lognormal modes, a nucleation mode with geometric mean diameters between 3 and $25 \mathrm{~nm}$, an Aitken mode with geometric mean diameters between 25 and $100 \mathrm{~nm}$, an accumulation with geometric mean diameters range from $100 \mathrm{~nm}$ to $1 \mu \mathrm{m}$, and a coarse mode with geometric mean diameters range from 1 to $5 \mu \mathrm{m}$. Second, the assumption is made that aerosols in a specific mode have common sources or have experienced similar aging processes, and the corresponding hygroscopic parameter $\kappa$ of aerosol particles at this mode is the same due to their similar chemical compositions. Hence, the HH-TDMA-measured $\kappa$ of aerosol particles at diameters of 50,100, 200 and $250 \mathrm{~nm}$ can be used to deduce the corresponding $\kappa$ of four modes of the fitted PNSD, and then get 
the size-resolved $\kappa$ for the full size range of PNSD. And more information about the size-resolved $\kappa$ can be found in Chen et al. (2012).

To use the core-shell coated code (BHCOAT, Bohren and Huffman, 2008; Cheng et al., 2009) for the Mie calculation, we need the diameters and complex refractive indices of the core and the shell. For core-shell mixed particles, the diameter of the core does not change as the RH changes and can be calculated using the following equation:

$D_{\text {core }}=D_{\mathrm{p}, \mathrm{dry}}\left(\frac{f_{\mathrm{LAC}}-f_{\mathrm{LAC}} \cdot r_{\mathrm{ext}-\mathrm{LAC}}}{1-f_{\mathrm{LAC}} \cdot r_{\mathrm{ext}-\mathrm{LAC}}}\right)^{\frac{1}{3}}$.

The complex refractive index of the core is set to be 1.80 $0.54 i$ (Ma et al., 2012). However, the shells of aerosol particles will take up water as a function of $\mathrm{RH}$ and be dissolved. Both the diameters and complex refractive indices of shells will change, and the complex refractive indices of shells are calculated with the following equation:

$\tilde{m}_{\text {shell }}=f_{\text {solute }} \cdot \tilde{m}_{\text {solute }}+\left(1-f_{\text {solute }}\right) \cdot \widetilde{m}_{\text {water }}$.

The volume fraction of solute, $f_{\text {solute }}$, follows:

$f_{\text {solute }}=\frac{D_{\mathrm{p}, \mathrm{dry}}^{3}-D_{\text {core }}^{3}}{D_{\mathrm{p}}^{3}(\mathrm{RH})-D_{\text {core }}^{3}}$,

where $\widetilde{m}_{\text {shell }}, \widetilde{m}_{\text {solute }}, \widetilde{m}_{\text {water }}$ are respectively the complex refractive indices of the shell, solute (assumed to be 1.53$10^{-7} i$; Wex et al., 2002), and water (i.e., $1.33-10^{-7} i$; Seinfeld and Pandis, 2006).

The SSA is defined as the ratio of the scattering coefficient to the extinction coefficient of aerosol particles. The scattering and absorption coefficients were calculated from the integration of the corresponding scattering and absorption efficiencies $\left(Q_{\mathrm{sp}}\right.$ and $\left.Q_{\mathrm{ap}}\right)$ over the whole number size distribution:

$\sigma_{\mathrm{sp} / \mathrm{ap}}=\int_{0}^{D_{\mathrm{p}}^{\max }} Q_{\mathrm{sp} / \mathrm{ap}} \cdot\left(\frac{\pi}{4} D_{\mathrm{p}}^{2}\right) \cdot N\left(\log D_{\mathrm{p}}\right) \cdot \mathrm{d} \log D_{\mathrm{p}}$,

where $Q_{\mathrm{sp}}$ and $Q_{\text {ap }}$ can be calculated through the BHCOAT code. Using Eq. (10), the $\sigma_{\mathrm{sp}}$ and $\sigma_{\mathrm{ap}}$ of externally mixed LAC and core-shell mixed aerosol particles can be calculated individually, and then added up to the total $\sigma_{\mathrm{sp}}$ and $\sigma_{\mathrm{ap}}$. Finally, SSA can be calculated according to its definition.
To calculate the $g$ of aerosol particles, the following equation (D'Almeida et al., 1991) is used:

$g=\frac{\sum_{i}\left(g_{\mathrm{ext}-\mathrm{LAC}}^{i} \sigma_{\mathrm{sp}, \mathrm{ext}-\mathrm{LAC}}^{i}+g_{\text {core-shell }}^{i} \sigma_{\mathrm{sp}, \text { core-shell }}^{i}\right)}{\sum_{i}\left(\sigma_{\mathrm{sp}, \text { ext-LAC }}^{i}+\sigma_{\mathrm{sp}, \text { core-shell }}^{i}\right)}$,

where $i$ represents the aerosol size bin, $\sigma_{\mathrm{sp} \text {,ext-LAC }}^{i}$ and $\sigma_{\text {sp,core-shell }}^{i}$ are, respectively, the scattering coefficients of externally mixed LAC and core-shell mixed aerosol particles at corresponding size. $g_{\text {ext-LAC }}^{i}$ and $g_{\text {core-shell }}^{i}$ are respectively the $g$ of externally mixed LAC and core-shell mixed aerosol at each size bin, which can be calculated using the BHCOAT code.

\subsection{Calculation of DARE and case design}

The calculated aerosol optical properties are used to evaluate the impacts of their diurnal changes on the estimates of daily average DARE. The temporal resolution of SSA and $g$ is about $10 \mathrm{~min}$, and hourly average data are used as inputs for radiative transfer model. Some cases are designed to evaluate the impact of diurnal variability of aerosol optical properties on the estimates of daily average DARE.

\subsubsection{Calculation of direct aerosol radiative effect}

DARE is either evaluated at the TOA or at the surface according to the following equation:

$F=\left(f_{\mathrm{a}} \downarrow-f_{\mathrm{a}} \uparrow\right)-\left(f_{0} \downarrow-f_{0} \uparrow\right)$.

In this expression, $F$ is the DARE, and $f$ denotes the downward/upward irradiance which spans $0.25-4 \mu \mathrm{m}$. $(f \downarrow-f \uparrow)$ denotes the net irradiance computed with a given aerosol $f_{\mathrm{a}}$, or without aerosol $f_{0}$, at either the TOA or surface.

The radiative transfer simulations are performed with the Santa Barbara DISORT (discrete ordinates radiative transfer) Atmospheric Radiative Transfer (SBDART) model (Ricchiazzi et al., 1998). We calculated DARE using the derived SSA and $g$ with diurnal pattern of AOD from an AERONET site, Xianghe. The Ångström exponents calculated with the aerosol extinction coefficient at 470 and $860 \mathrm{~nm}$ are used to account for the spectral dependence of AOD. Moreover, SSA and $g$ at four wavelengths (470, 550, 860 and $1240 \mathrm{~nm}$ ) are used as input of the SBDART model. The atmospheric profile of mid-latitude summer provided by SBDART itself is used in simulations. The information of surface albedo is obtained from MCD43C 3 albedo product (https://lpdaac.usgs.gov/products/modis_products_table/ $\operatorname{mcd} 43 \mathrm{c} 3$ ). And the value of surface albedo at Wuqing at 1 August 2009 is used to perform the calculation of DARE corresponding to average diurnal variations of AOD, SSA and $g$, and the surface albedo values for wavelengths at 470 , $550,670,860,1240,1640$ and $2100 \mathrm{~nm}$ are $0.152,0.158$, 
$0.144,0.212,0.209,0.174$ and 0.119 . To obtain the daily average DARE, the calculations are performed with a $1 \mathrm{~h}$ time step within the local time range from local time 06:00 to 18:00, and then averaged over $24 \mathrm{~h}$. The local time range from 06:00 to 18:00 is approximately the time period from sunrise to sunset.

\subsubsection{Case design}

Several cases are designed to evaluate the impacts of the diurnal variations of aerosol optical properties on the daily average DARE. The designed cases are listed in Table 1. The abbreviation FT stands for full temporal. $\overline{\mathrm{dt}}, \overline{\mathrm{am}}, \overline{\mathrm{pm}}$, and $\overline{\mathrm{ap}}$ indicate that the aerosol optical properties are averaged over four different time periods: daytime, early morning, late afternoon, and both early morning and late afternoon. Early morning is defined by the period when SZA is within 50 and $70^{\circ}$ in the morning, corresponding to local time of 07:00 and 08:00 in this study. Late afternoon is defined by the period when SZA is within $50^{\circ}$ and $70^{\circ}$ in the afternoon, corresponding to local time of 16:00 and 17:00. These specified early morning and late afternoon periods mimic the AERONET sampling periods used for retrieving SSA and $g$ (Kassianov et al., 2013). Among all these cases, Case 1 is supposed to be the reference case because SSA and $g$ in Case 1 are both for ambient conditions with the diurnal changes of AOD also considered. Case 2 is designed to study the impacts of the daily averages of AOD, SSA and $g$ on the DARE. Cases 3-8 are designed to investigate the sensitivity of daily average DARE to the diurnal changes of AOD, SSA and $g$. Cases 9-11 are designed to test how the daily average DARE responds if the SSA and $g$ are both averaged over either early morning, late afternoon or both early morning and late afternoon. For cases 2-11, the actual diurnal variations of selected aerosol optical properties are ignored, and the corresponding averages are used instead.

To estimate the difference between a specified case and the reference case, we define the relative difference (RD) as follows:

$\mathrm{RD}=\frac{F_{\text {case }}-F_{\text {case } 1}}{F_{\text {case } 1}} \times 100 \%$,

where $F_{\text {case }}$ is the daily average DARE at the TOA/surface of specified case, $F_{\text {case } 1}$ is the daily average DARE at the TOA/surface of Case 1.

\section{Results and discussions}

\subsection{Diurnal variations of aerosol optical properties}

The diurnal variation of AOD at $550 \mathrm{~nm}$ in Xianghe summer is presented in Fig. 1. AOD at $550 \mathrm{~nm}$ is calculated using the AOD at $500 \mathrm{~nm}$ and the Ångström exponent between 440 and $675 \mathrm{~nm}$ provided by AERONET AOD product. The daily average AOD at $550 \mathrm{~nm}$ is 0.47 , which means that the NCP is

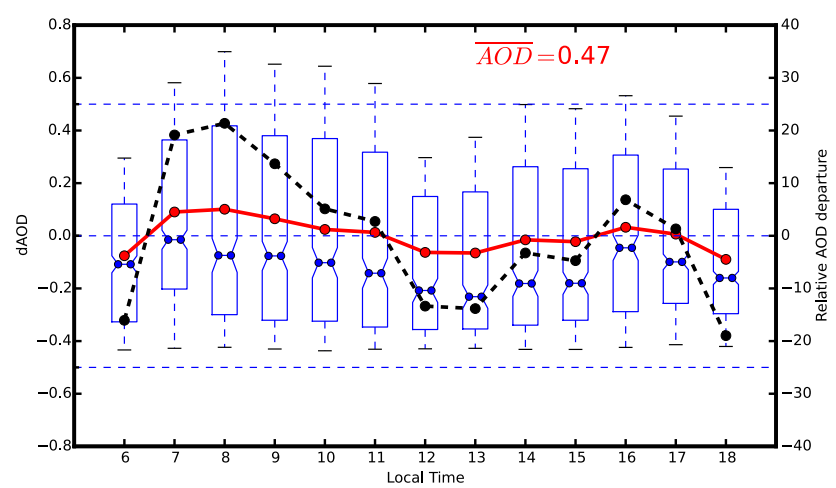

Figure 1. The average diurnal pattern of AOD at $550 \mathrm{~nm}$ from AERONET measurements, Xianghe summer. Red line represents the absolute AOD departures (dAOD) from daily mean. Box plots give absolute AOD departure range from 25th to 75th percentile, and bars outside the boxes give the range within 5 th to 95 th percentile; the blue dots in the box are medians. Black solid points give the relative departures in the right axis.

highly polluted. The value of AOD between 07:00 and 08:00 in the morning, and that at 16:00 in the afternoon are relatively higher, and the relative departures of AOD from daily mean can be up to $20 \%$ on average.

Using the method mentioned in Sect. 3, SSA and $g$ are calculated from the observation. The obtained SSA and $g$ have a temporal resolution of about $10 \mathrm{~min}$, and are averaged to $1 \mathrm{~h}$ data to show their diurnal variations. Those days without a full temporal coverage of SSA or $g$ are excluded; thus, 17 days are available. Only the local time range from 06:00 to 18:00 is considered, since the direct interaction of aerosol with the solar shortwave radiation only happens during daytime.

The average diurnal variations of SSA at $550 \mathrm{~nm}$ for the ambient and the dry state aerosols during the observation period are illustrated in Fig. 2. It can be seen from the graph that the diurnal pattern of SSA at the two states are quite different. At dry conditions, the SSA reaches minimum in the morning and evening, and maximum at noon, with an average of 0.86 . This result is similar to most previous studies on the diurnal variation of SSA for dry state aerosol (He et al., 2009; Fan et al., 2010; Junwei et al., 2012; Gyawali et al., 2012). For ambient aerosol, many of the aerosol components are hygroscopic and can take up water as a function of RH (Bian et al., 2014; Cheng et al., 2008), making the SSA change as the RH changes. In this study, our results demonstrate that the diurnal variation of SSA for ambient aerosol is evident. The SSA reaches maximum in the morning when $\mathrm{RH}$ is the highest and minimum in the afternoon, difference between the maximum and minimum can be up to 0.06 , with the average at 0.91 . Due to the hygroscopic growth of aerosol particles, the scattering coefficient will be largely enhanced when RH is greater than $60 \%$ (Cheng et al., 2008). However, the dependence of aerosol absorption on $\mathrm{RH}$ is not as 
Table 1. Designed cases.

\begin{tabular}{lccccccccccc}
\hline & Case 1 & Case 2 & Case 3 & Case 4 & Case 5 & Case 6 & Case 7 & Case 8 & Case 9 & Case 10 & Case 11 \\
\hline AOD & FT & $\overline{\mathrm{dt}}$ & $\overline{\mathrm{am}}$ & $\overline{\mathrm{pm}}$ & $\overline{\mathrm{dt}}$ & $\overline{\mathrm{dt}}$ & $\overline{\mathrm{dt}}$ & $\overline{\mathrm{dt}}$ & $\overline{\mathrm{dt}}$ & $\overline{\mathrm{dt}}$ & $\overline{\mathrm{dt}}$ \\
SSA & FT & $\overline{\mathrm{dt}}$ & $\overline{\mathrm{dt}}$ & $\overline{\mathrm{dt}}$ & $\overline{\mathrm{am}}$ & $\overline{\mathrm{pm}}$ & $\overline{\mathrm{dt}}$ & $\overline{\mathrm{dt}}$ & $\overline{\mathrm{am}}$ & $\overline{\mathrm{pm}}$ & $\overline{\mathrm{ap}}$ \\
$g$ & FT & $\overline{\mathrm{dt}}$ & $\overline{\mathrm{dt}}$ & $\overline{\mathrm{dt}}$ & $\overline{\mathrm{dt}}$ & $\overline{\mathrm{dt}}$ & $\overline{\mathrm{am}}$ & $\overline{\mathrm{pm}}$ & $\overline{\mathrm{am}}$ & $\overline{\mathrm{pm}}$ & $\overline{\mathrm{ap}}$ \\
\hline
\end{tabular}

FT : full temporal; $\overline{\mathrm{dt}}$ : averaged over daytime (06:00 to 18:00), $\overline{\mathrm{am}}$ : averaged over early morning; $\overline{\mathrm{pm}}$ : averaged over late afternoon; $\overline{\mathrm{ap}}$ : averaged over early morning and late afternoon; early morning: $50^{\circ} \leq \mathrm{SZA} \leq 70^{\circ}$ in the morning; late afternoon: $50^{\circ} \leq \mathrm{SZA} \leq 70^{\circ}$ in the afternoon.

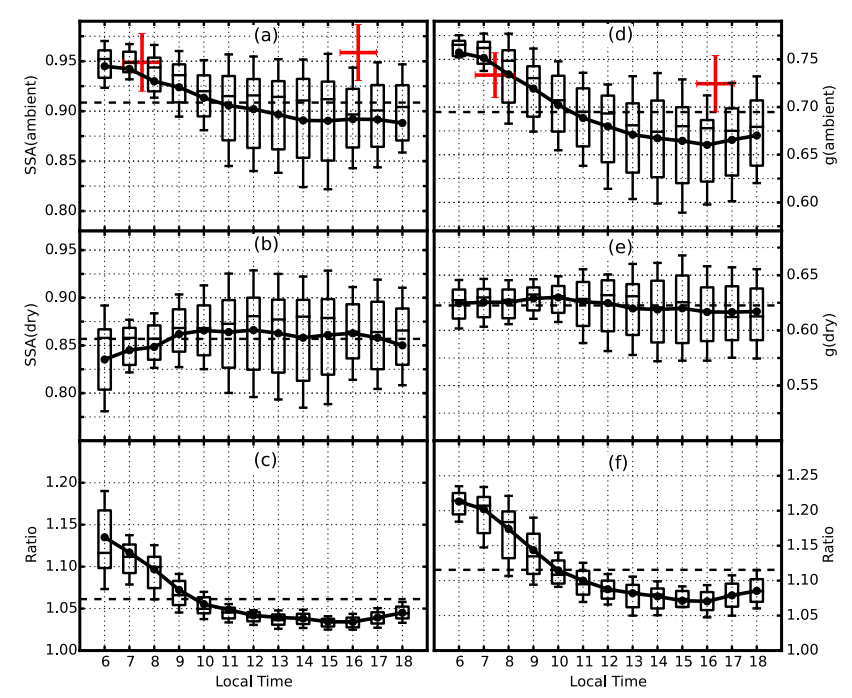

Figure 2. The diurnal variations of SSA and $g$ at $550 \mathrm{~nm}$, (a) average diurnal pattern of SSA for ambient aerosol and average SSA at $440 \mathrm{~nm}$ from AERONET site Xianghe (red plus symbol); (b) average diurnal pattern of SSA for dry-state aerosol; (c) the ratio between (a) and (b); (d) average diurnal pattern of $g$ for ambient aerosol and average $g$ at $440 \mathrm{~nm}$ from AERONET site Xianghe (red plus symbol); (e) average diurnal pattern of $g$ for dry state aerosol; (f) the ratio between (d) and (e). Black lines are the average diurnal variations, and dashed lines are their corresponding averages. Box plots give the data points range from 25 th to 75 th percentile, and bars outside the boxes give the range within 5th to 95 th percentile. Lines in boxes are medians. The $x$ and $y$ dimensions of the red plus symbol represent the standard deviations of SSA or $g$ and the local time when data points are sampled, respectively.

significant as that of scattering (Redemann et al., 2001; Tao et al., 2014). According to the definition of SSA, its diurnal variation will be largely influenced by RH, especially when $\mathrm{RH}$ is high. The average diurnal pattern of RH during the corresponding period is shown in Fig. 3. RH begins to decrease in the morning at 06:00, and reaches minimum in the afternoon. And the RH during this observation period is frequently higher than $60 \%$. Hence, it can be seen from Fig. 2 that the diurnal pattern of SSA for ambient aerosol is dominated by but not completely consistent with that of RH. Due to the RH in the afternoon is not high enough, and the SSA of dry state aerosol will play a role. The diurnal pattern of the ratio between the SSA of ambient and dry state aerosol is highly correlated with that of $\mathrm{RH}$, and the daily average ratio is 1.06 .

The average diurnal patterns of $g$ at $550 \mathrm{~nm}$ for dry state aerosol and ambient aerosol during the observation period are also illustrated in Fig. 2. It is obvious that the diurnal changes of $g$ at two states are quite different. The $g$ of dry state aerosol shows little variability during daytime, and its daily average is 0.62 . On the contrary, $g$ of ambient aerosol has evident diurnal variation. Like SSA, the $g$ reaches maximum in the morning when RH is the highest and minimum in the afternoon when RH is the lowest, difference between the maximum and minimum can be up to 0.1 , with the average at 0.70 . The diurnal pattern of $g$ for ambient aerosol is highly correlated with that of RH. The diurnal pattern of the ratio between $g$ of ambient and dry state aerosol is also consistent with that of RH, and the daily average ratio is 1.12 . This can be easily understood, because $g$ of dry state aerosol shows little variation during daytime, the diurnal pattern of $g$ for ambient aerosol is mainly dominated by the diurnal pattern of RH.

In addition, the average SSA and $g$ at $440 \mathrm{~nm}$ from AERONET site Xianghe during periods from July to August of years from 2001 to 2013 are also shown in Fig. 2a and d, respectively. There are 91 days available for SSA with both morning and afternoon observation valid, and 144 days for $g$. The results demonstrate that the evident morning to afternoon contrast of SSA and $g$ mentioned before are not seen in SSA and $g$ observed from AERONET measurements. In those AERONET results, $g$ in the early morning is slightly higher than that in the late afternoon; however, on the contrary, SSA in the late afternoon is slightly higher than that in the early morning. Two reasons may be responsible for this discrepancy: (1) the SSA and $g$ calculated in this research are based on in situ measurements; however, SSA and $g$ provided by AERONET measurements are columnar properties; (2) different time periods of those two data sets.

\subsection{The impacts of diurnal variations of aerosol optical properties on the estimation of daily average DARE}

The average diurnal patterns of AOD, SSA and $g$ introduced in Sect. 4.1 are used to estimate the overall influence of their diurnal changes on the estimation of DARE. The influences at the TOA and surface are evaluated separately, and the de- 


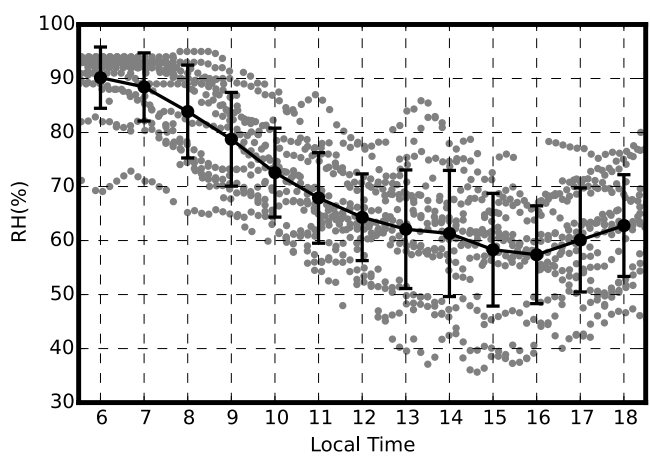

Figure 3. The scatter plots of RH for selected days, the black line is the average diurnal variation of $\mathrm{RH}$.

signed cases are introduced in Sect. 3.2.2. Results of this assessment are shown in Fig. 4, corresponding to the TOA and surface respectively. The $24 \mathrm{~h}$ average DARE for Case 1 at the TOA and surface are -8.28 and $-32.51 \mathrm{~W} \mathrm{~m}^{-2}$, respectively. The small differences in Case 2 at the TOA and surface demonstrate that an accurate prediction of daily average DARE can be achieved by using the daily averages of AOD, SSA, and $g$, even when their diurnal variations are all evident. For Case 3, it leads to an overestimation of the negative daily average DARE at the TOA and surface, due to the overestimation of AOD averaged over early morning. This means, if the temporal coverage of AOD is incomplete, it might result in a large bias in the estimation of daily average DARE at the TOA and surface when the diurnal variation of AOD is significant. A similar conclusion is reached from previous studies (Arola et al., 2013; Kassianov et al., 2013). However, for Case 4, due to the AOD averaged over late afternoon being very close to its daytime average, the relative difference is very small. In cases 5 and 6 , the SSA averaged over the early morning or late afternoon is used. As a result, the estimated daily average DARE shows large biases. A larger SSA will cause less absorbing of incident solar radiation by atmospheric aerosol, more light reaches the surface and reflected into space. The overestimation of SSA in the early morning will therefore result in a stronger negative radiative effect (NRE) at the TOA and weaker NRE at surface. In cases 7 and 8 , the $g$ averaged over the early morning or late afternoon is used, it will also lead to large biases in the estimation of daily average DARE at the TOA. With the increase of $g$, more light will be forward scattered, absorbed by the atmospheric aerosol, and reaches the surface. Consequently, the overestimation of $g$ in the early morning will result in weaker NRE at the TOA and surface. The results from cases 5-8 indicate the diurnal variations of SSA and $g$ in the NCP have significant impacts on the estimation of DARE at the TOA, but less impacts on the estimation of DARE at surface. If the temporal resolution of SSA and $g$ is not high enough to accurately represent their diurnal variations, the estimated daily average DARE at the TOA might be biased significantly.
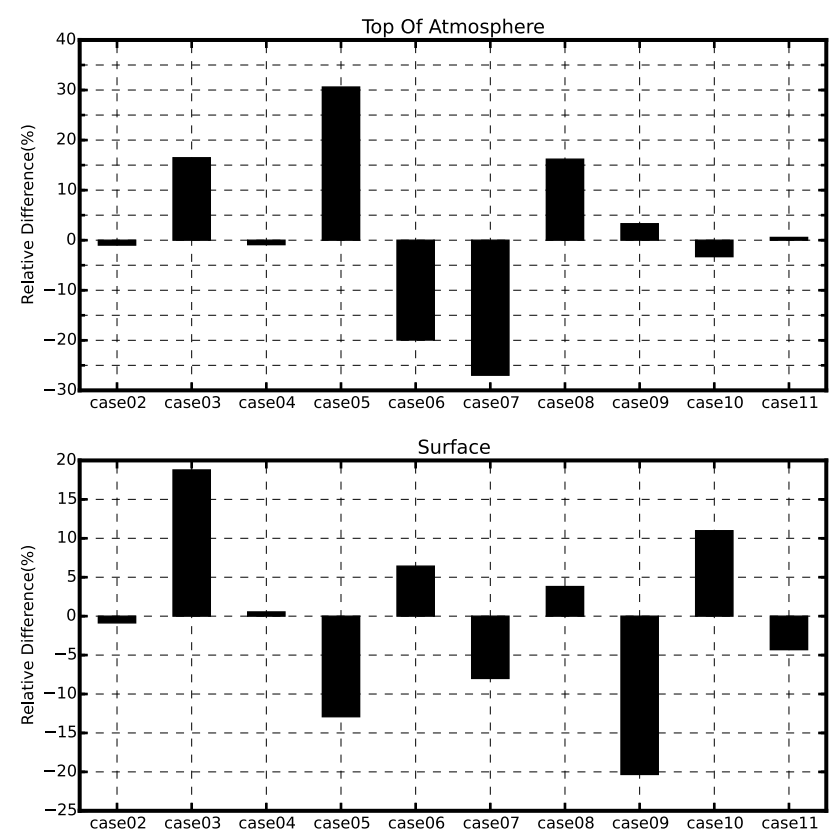

Figure 4. Relative differences compared to Case 1 of different cases at the TOA and surface.

In Case 9, the SSA and $g$ are both averaged over early morning, and daily average AOD is used. The results show that this treatment has less influence on the estimation of daily average DARE at the TOA, but larger influences at surface than those in cases 5 and 7. According to the analysis of cases 5-8, the overestimation of SSA will lead to stronger NRE at the TOA and weaker NRE at surface. The overestimation of $g$ will result in weaker NRE at the TOA and surface. The effect of the overestimation of SSA and $g$ will be canceled out to some extent at the TOA, but enhanced at the surface, and vice versa in Case 10. In Case 11, the results demonstrate that both SSA and $g$ averaged over early morning and late afternoon only has little influence on the estimation of daily average DARE at the TOA and surface. Conclusions can be made that, overall, for estimating DARE at the TOA, schemes of cases 9-11 can largely improve the results compared to cases 5-8. Case 11 is the best and also suitable for estimating DARE at surface.

The RD results of cases at the TOA for individual days with specific diurnal variations of SSA and $g$, and also the absolute values and day-to-day variability of DARE for Case 1 are shown in Fig. 5. The diurnal patterns of AOD for all days are fixed, and is the same as the one introduced in Sect. 4.1. This means that the evident day-to-day variability of DARE for Case 1 shown in Fig. 5 is driven by the day-to-day variability of SSA and $g$. Overall, the RD results from cases shown in Fig. 5c for different days are consistent with the results from cases aforementioned. For Case 2, its results are very stable and close to zero which means that even the diurnal patterns of SSA and $g$ are not completely consistent with 


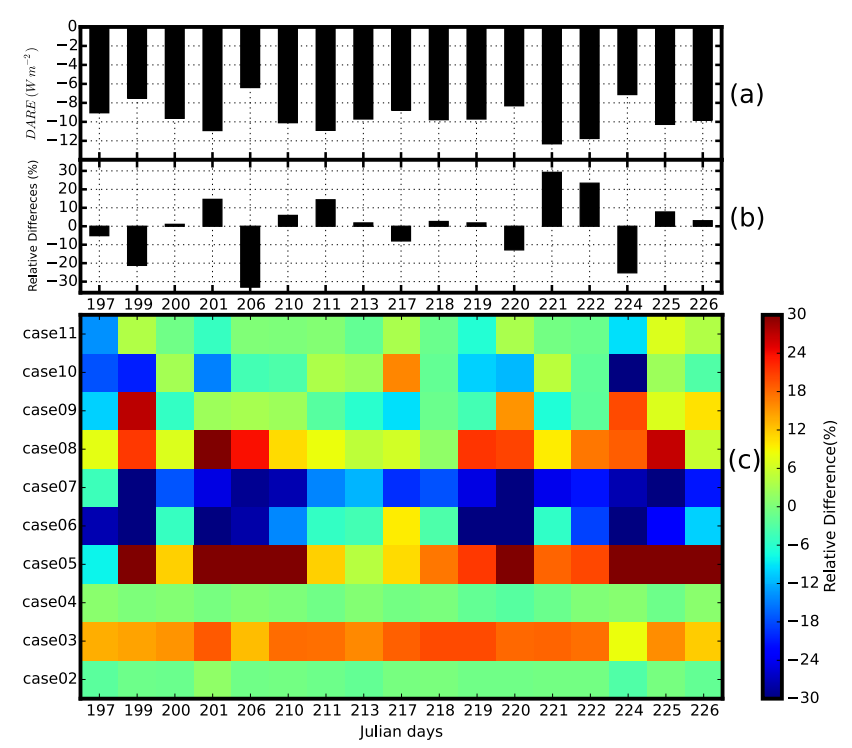

Figure 5. (a) The absolute values of $24 \mathrm{~h}$ average DARE in $\mathrm{W} \mathrm{m} \mathrm{m}^{-2}$ at the TOA for Case 1; (b) the relative differences of DARE values at the TOA of Case 1 compared to its 17-day average; (c) the relative differences compared to Case 1 of different cases for different days at the TOA.

the their average pattern introduced in Sect. 4.1, their daytime averages are enough to provide a accurate estimation of DARE. For cases 3 and 4, due to the diurnal patterns of AOD for 17 valid days are the same one, their results vary little among 17 selected days. For cases 5-8, it can be seen from Fig. 5, high variability existed in their results. Using Case 5 as an example, it corresponds to the case in which the daytime average of AOD and $g$, and the early morning average of SSA are used. Hence its variation compared to Case 2 is induced by the variation of the difference between the early morning average and daytime average of SSA (DEDSSA). The day-to-day variation of DEDSSA is presented in Fig. 6; it is clear that its variability is consistent with the variability of $\mathrm{RD}$ results of Case 5 shown in Fig. 5c. In addition, the differences between the early morning average and the daytime average of RH (DEDRH) are also shown in Fig. 6; it shows that the pattern of day-to-day variation of DEDSSA is completely consistent with the pattern of DEDRH. This results demonstrate that the high variability of the RD results of Case 5 is driven by the variation of $\mathrm{RH}$, and also the results of cases 6-8. For cases 9-11, their performances are much better than those of cases 5-8. In particular, the results of Case 11 are very stable and close to the results of Case 2. This means that, even if the diurnal variations of SSA and $g$ are not in exact accordance with the average pattern mentioned in Sect. 4.1, the scheme of Case 11 still can lead to a good result. But exception still exists for Case 11: the relative difference on Julian day 197 is notably larger than that in other days, and the least improvement compare to results of other cases. It is found that the diurnal variation of $\mathrm{RH}$ on this day is quite different from the one introduced in Sect. 4.1. The diurnal variations of SSA, $g$ and RH on Julian day 197 are shown in Fig. 7. It is clear that the diurnal variations of SSA and $g$ are dominated by the diurnal variation of RH, but not like their typical pattern in those selected days. There are two reasons that the results of Case 11 are very small and stable on most days. First, the diurnal pattern of SSA and $g$ are both dominated by the diurnal variation of RH; thus the SSA and $g$ are both highest at dawn and lowest in the late afternoon, the SSA and $g$ averaged over early morning and late afternoon will be closer to their daily averages than cases 9 and 10. Second, according to the analysis for the results of cases 9 and 10, the SSA and $g$ have opposite effects on the estimation of daily averaged DARE at the TOA, the influence of SSA will be offset to some extent by that of $g$. Therefore, the diurnal pattern of $\mathrm{RH}$ is an important factor which determines if the scheme of Case 11 can be used to improve the estimation of daily average DARE. On the other hand, the results of cases 9 and 10 are not as stable as that of Case 11, but still much better than those of cases 5-8. The diurnal pattern of RH shown in Fig. 3 is prevalent in many regions around the world (Ephrath et al., 1996; Gebhart et al., 2001; Fan et al., 2010; Sun et al., 2013); the scheme of Case 11 maybe also suitable for these regions when the RH is frequently higher than $60 \%$, especially for regions where aerosol particles are similar or more hygroscopic compared to the hygroscopicity of aerosols introduced in this research. We suggest that using the scheme of Case 11 to improve the accurate estimation of DARE. If the temporal samplings of SSA and $g$ are too few to adopt the scheme of Case 11, schemes of cases 9 and 10 still can be good options for improving the estimation of DARE at the TOA. The results of cases 5-8 demonstrate that the diurnal changes of SSA and $g$ have significant influences on the estimation of DARE. However, the RD results of Case 11 are much smaller than the day-to-day variability of DARE for Case 1 shown in Fig. 5b, which indicate that if the diurnal patterns of SSA and $g$ are consistent with those introduced in this research, observing incomplete diurnal cycles of SSA and $g$ have only second-order consequences on direct radiative effect estimates.

\section{Conclusions}

SSA and $g$ are both important parameters in the estimation of DARE (McComiskey et al., 2008), but their diurnal variations are rarely investigated, especially in the NCP. In this paper, using the in situ measurements from HaChi campaign, the diurnal variations of SSA and $g$ are studied. The results show that, for ambient aerosol, the diurnal patterns of SSA and $g$ are both highest at dawn and lowest in the late afternoon, and quite different from those of dry state aerosol. For dry state aerosol, the SSA reaches minimum in the morning and evening, and maximum at noon, with the average at 0.86 . For ambient aerosol, the SSA reaches maximum at 

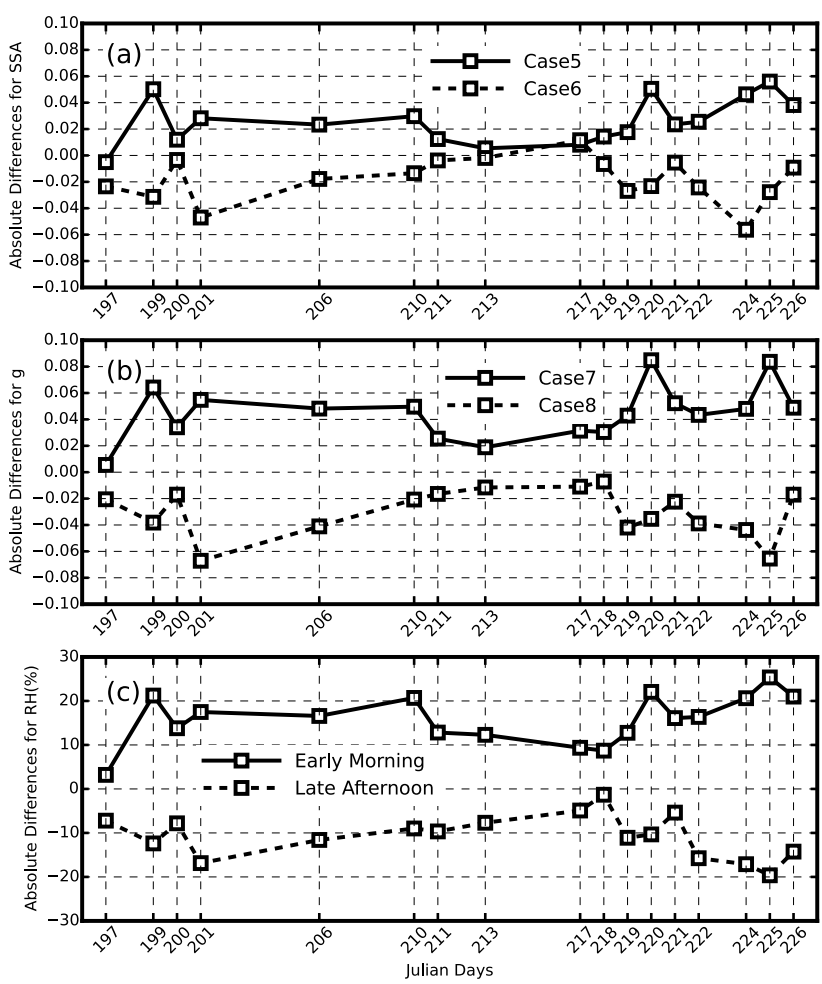

Figure 6. The absolute differences between early morning (or late afternoon) average and the daytime average of SSA, $g$, and RH. (a) for SSA: corresponding to cases 5 and 6; (b) for $g$ : corresponding to cases 7 and 8; (c) for RH.

dawn when RH is the highest and minimum in the afternoon, difference between the maximum and minimum can be up to 0.06 , with the average at 0.91 . The diurnal pattern of SSA for ambient aerosol is dominated by that of $\mathrm{RH}$, and the average ratio between the SSA of ambient and dry state aerosol is 1.06. On the other hand, the $g$ of dry state aerosol shows little variability during daytime, with an average of 0.62 . The diurnal pattern of $g$ for ambient aerosol is also evident and dominated by that of $\mathrm{RH}$, the difference between the maximum and minimum can be up to 0.1 , with an average of 0.70 . The average ratio of $g$ for ambient aerosol to that for dry state aerosol is 1.12 .

Using the SSA and $g$ calculated from in situ measurements, and AOD from AERONET measurements, several cases are designed to evaluate the impacts of the diurnal changes of AOD, SSA and $g$ on the estimates of daily average DARE. The results demonstrate that the diurnal changes of SSA and $g$ in the NCP have significant influence on the estimation of DARE at the TOA, which means that if the temporal samplings of SSA and $g$ are incomplete, significant errors may occur in the estimation of DARE at the TOA. If the full temporal coverage of AOD, SSA and $g$ are available, the accurate estimation of DARE can be achieved by using the daily averages of AOD, SSA and $g$. However, due to the lack of full temporal coverage data sets of SSA and $g$, their

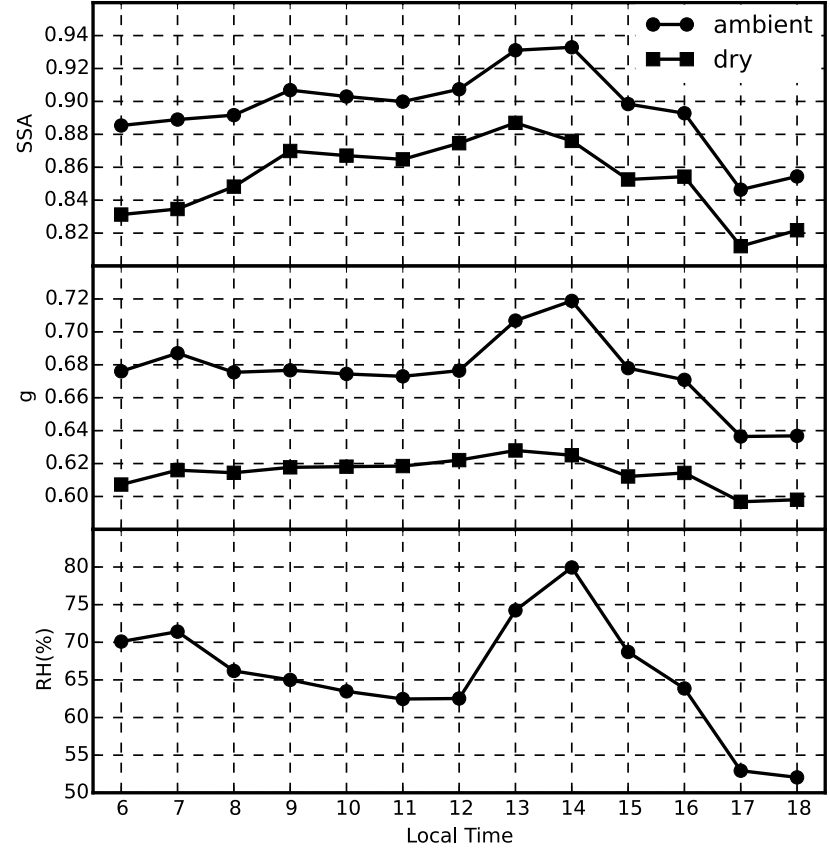

Figure 7. The diurnal variations of SSA, $g$ and RH on Julian day 197.

daily averages are usually not available. Regarding this, three cases are designed in order to find some suggestions about the estimation of daily average DARE. We conclude that, if the RH plays a dominant role in the diurnal variations of SSA and $g$, an accurate estimation of DARE can be achieved by using SSA and $g$ averaged over early morning and late afternoon as inputs for radiative transfer model. If the samplings of SSA or $g$ are only available in the early morning or late afternoon, either averaged over early morning or late afternoon of both SSA and $g$ can be used to improve the estimation of DARE at the TOA. Those important findings indicate that the diurnal changes of SSA and $g$ have significant influence on the estimation of DARE. However, if the diurnal patterns of SSA and $g$ are consistent with those introduced in this research, observing incomplete diurnal cycles of SSA and $g$ have only second-order consequences on direct radiative effect estimates. It may allow one to bypass the complex temporal monitoring problems associated with significant diurnal changes of SSA and $g$. This study will further our understanding of the diurnal characteristics of SSA and $g$ in the NCP and help to improve the accurate estimation of DARE. 
Acknowledgements. We acknowledge the free use of MODIS surface albedo product and AOD measurements from AERONET. This work is supported by the National 973 project of China (2011CB403402), the National Natural Science Foundation of China (41375134) and the Beijing Natural Science Foundation (b8131003).

Edited by: V.-M. Kerminen

\section{References}

Arola, A., Eck, T. F., Huttunen, J., Lehtinen, K. E. J., Lindfors, A. V., Myhre, G., Smirnov, A., Tripathi, S. N., and Yu, H.: Influence of observed diurnal cycles of aerosol optical depth on aerosol direct radiative effect, Atmos. Chem. Phys., 13, 78957901, doi:10.5194/acp-13-7895-2013, 2013.

Bellouin, N., Boucher, O., Haywood, J., and Reddy, M. S.: Global estimate of aerosol direct radiative forcing from satellite measurements, Nature, 438, 1138-1141, 2005.

Bellouin, N., Jones, A., Haywood, J., and Christopher, S. A.: Updated estimate of aerosol direct radiative forcing from satellite observations and comparison against the Hadley Centre climate model, J. Geophys. Res.-Atmos., 113, D10205, doi:10.1029/2007JD009385, 2008.

Bellouin, N., Quaas, J., Morcrette, J.-J., and Boucher, O.: Estimates of aerosol radiative forcing from the MACC re-analysis, Atmos. Chem. Phys., 13, 2045-2062, doi:10.5194/acp-13-20452013, 2013.

Bian, Y. X., Zhao, C. S., Ma, N., Chen, J., and Xu, W. Y.: A study of aerosol liquid water content based on hygroscopicity measurements at high relative humidity in the North China Plain, Atmos. Chem. Phys., 14, 6417-6426, doi:10.5194/acp-14-64172014, 2014.

Birmili, W., Stratmann, F., and Wiedensohler, A.: Design of a DMA-based size spectrometer for a large particle size range and stable operation, J. Aerosol Sci., 30, 549-553, doi:10.1016/s0021-8502(98)00047-0, 1999.

Bohren, C. F. and Huffman, D. R.: Absorption and scattering of light by small particles, Wiley, New York, USA, 2008.

Bond, T. C., Doherty, S. J., Fahey, D., Forster, P., Berntsen, T., DeAngelo, B., Flanner, M., Ghan, S., Kärcher, B., and Koch, D.: Bounding the role of black carbon in the climate system: A scientific assessment, J. Geophys. Res.-Atmos., 118, 5380-5552, 2013.

Boucher, O.: On aerosol direct shortwave forcing and the HenyeyGreenstein phase function, J. Atmos. Sci., 55, 128-134, doi:10.1175/1520-0469(1998)055<0128:oadsfa>2.0.co;2, 1998.

Chen, J., Zhao, C. S., Ma, N., Liu, P. F., Göbel, T., Hallbauer, E., Deng, Z. Z., Ran, L., Xu, W. Y., Liang, Z., Liu, H. J., Yan, P., Zhou, X. J., and Wiedensohler, A.: A parameterization of low visibilities for hazy days in the North China Plain, Atmos. Chem. Phys., 12, 4935-4950, doi:10.5194/acp-12-4935-2012, 2012.

Cheng, Y., Wiedensohler, A., Eichler, H., Heintzenberg, J., Tesche, M., Ansmann, A., Wendisch, M., Su, H., Althausen, D., and Herrmann, H.: Relative humidity dependence of aerosol optical properties and direct radiative forcing in the surface boundary layer at Xinken in Pearl River Delta of China: An observation based numerical study, Atmos. Environ., 42, 6373-6397, 2008.
Cheng, Y. F., Berghof, M., Garland, R. M., Wiedensohler, A., Wehner, B., Müller, T., Su, H., Zhang, Y. H., Achtert, P., Nowak, A., Pöschl, U., Zhu, T., Hu, M., and Zeng, L. M.: Influence of soot mixing state on aerosol light absorption and single scattering albedo during air mass aging at a polluted regional site in northeastern China, J. Geophys. Res.-Atmos., 114, D00G10, doi:10.1029/2008JD010883, 2009.

Chung, C. E., Ramanathan, V., Kim, D., and Podgorny, I. A.: Global anthropogenic aerosol direct forcing derived from satellite and ground-based observations, J. Geophys. Res.-Atmos., 110, D24207, doi:10.1029/2005jd006356, 2005.

D’Almeida, G. A., Koepke, P., and Shettle, E. P.: Atmospheric aerosols: global climatology and radiative characteristics, A. Deepak Pub., Va, 1991.

Dubovik, O., Smirnov, A., Holben, B., King, M., Kaufman, Y., Eck, T., and Slutsker, I.: Accuracy assessments of aerosol optical properties retrieved from Aerosol Robotic Network (AERONET) Sun and sky radiance measurements, J. Geophys. Res.-Atmos., 105, 9791-9806, 2000.

Ephrath, J. E., Goudriaan, J., and Marani, A.: Modelling diurnal patterns of air temperature, radiation wind speed and relative humidity by equations from daily characteristics, Agric. Syst., 51, 377-393, doi:10.1016/0308-521X(95)00068-G, 1996.

Fan, X., Chen, H., Xia, X., Li, Z., and Cribb, M.: Aerosol optical properties from the Atmospheric Radiation Measurement Mobile Facility at Shouxian, China, J. Geophys. Res.-Atmos., 115, D00K33, doi:10.1029/2010jd014650, 2010.

Gebhart, K. A., Copeland, S., and Malm, W. C.: Diurnal and seasonal patterns in light scattering, extinction, and relative humidity, Atmos. Environ., 35, 5177-5191, doi:10.1016/S13522310(01)00319-3, 2001.

Gyawali, M., Arnott, W. P., Zaveri, R. A., Song, C., Moosmüller, H., Liu, L., Mishchenko, M. I., Chen, L.-W. A., Green, M. C., Watson, J. G., and Chow, J. C.: Photoacoustic optical properties at UV, VIS, and near IR wavelengths for laboratory generated and winter time ambient urban aerosols, Atmos. Chem. Phys., 12, 2587-2601, doi:10.5194/acp-12-2587-2012, 2012.

He, X., Li, C. C., Lau, A. K. H., Deng, Z. Z., Mao, J. T., Wang, M. H., and Liu, X. Y.: An intensive study of aerosol optical properties in Beijing urban area, Atmos. Chem. Phys., 9, 8903-8915, doi:10.5194/acp-9-8903-2009, 2009.

Hennig, T., Massling, A., Brechtel, F. J., and Wiedensohler, A.: A tandem DMA for highly temperature-stabilized hygroscopic particle growth measurements between $90 \%$ and $98 \%$ relative humidity, J. Aerosol Sci., 36, 1210-1223, doi:10.1016/j.jaerosci.2005.01.005, 2005.

Holben, B., Eck, T., Slutsker, I., Tanre, D., Buis, J., Setzer, A., Vermote, E., Reagan, J., Kaufman, Y., and Nakajima, T.: AERONET - A federated instrument network and data archive for aerosol characterization, Remote Sens. Environ., 66, 1-16, 1998.

Holben, B., Eck, T., Slutsker, I., Smirnov, A., Sinyuk, A., Schafer, J., Giles, D., and Dubovik, O.: AERONET's version 2.0 quality assurance criteria, Remote Sensing of the Atmosphere and Clouds, Proc. SPIE 6408, 64080Q, doi:10.1117/12.706524, 2006.

Junwei, X., Jun, T., Renjian, Z., Tiantao, C., Chunpeng, L., Jianmin, C., Guanghan, H., Xiang, L., and Zhaoqin, Z.: Measurements of surface aerosol optical properties in winter of Shanghai, Atmos. 
Res., 109-110, 25-35, doi:10.1016/j.atmosres.2012.02.008, 2012.

Kassianov, E., Barnard, J., Pekour, M., Berg, L. K., Michalsky, J., Lantz, K., and Hodges, G.: Do diurnal aerosol changes affect daily average radiative forcing?, Geophys. Res. Lett., 40, 32653269, doi:10.1002/grl.50567, 2013.

Kaufman, Y. J., Holben, B. N., Tanré, D., Slutsker, I., Smirnov, A., and Eck, T. F.: Will aerosol measurements from Terra and Aqua Polar Orbiting satellites represent the daily aerosol abundance and properties?, Geophys. Res. Lett., 27, 3861-3864, doi:10.1029/2000GL011968, 2000.

Liu, H. J., Zhao, C. S., Nekat, B., Ma, N., Wiedensohler, A., van Pinxteren, D., Spindler, G., Müller, K., and Herrmann, H.: Aerosol hygroscopicity derived from size-segregated chemical composition and its parameterization in the North China Plain, Atmos. Chem. Phys., 14, 2525-2539, doi:10.5194/acp-14-25252014, 2014.

Liu, P. F., Zhao, C. S., Göbel, T., Hallbauer, E., Nowak, A., Ran, L., Xu, W. Y., Deng, Z. Z., Ma, N., Mildenberger, K., Henning, S., Stratmann, F., and Wiedensohler, A.: Hygroscopic properties of aerosol particles at high relative humidity and their diurnal variations in the North China Plain, Atmos. Chem. Phys., 11, 3479-3494, doi:10.5194/acp-11-3479-2011, 2011.

Ma, N., Zhao, C. S., Nowak, A., Müller, T., Pfeifer, S., Cheng, Y. F., Deng, Z. Z., Liu, P. F., Xu, W. Y., Ran, L., Yan, P., Göbel, T., Hallbauer, E., Mildenberger, K., Henning, S., Yu, J., Chen, L. L., Zhou, X. J., Stratmann, F., and Wiedensohler, A.: Aerosol optical properties in the North China Plain during HaChi campaign: an in-situ optical closure study, Atmos. Chem. Phys., 11, 5959-5973, doi:10.5194/acp-11-5959-2011, 2011.

Ma, N., Zhao, C. S., Müller, T., Cheng, Y. F., Liu, P. F., Deng, Z. Z., Xu, W. Y., Ran, L., Nekat, B., van Pinxteren, D., Gnauk, T., Müller, K., Herrmann, H., Yan, P., Zhou, X. J., and Wiedensohler, A.: A new method to determine the mixing state of light absorbing carbonaceous using the measured aerosol optical properties and number size distributions, Atmos. Chem. Phys., 12, 23812397, doi:10.5194/acp-12-2381-2012, 2012.

Mazzola, M., Lanconelli, C., Lupi, A., Busetto, M., Vitale, V., and Tomasi, C.: Columnar aerosol optical properties in the Po Valley, Italy, from MFRSR data, J. Geophys. Res.-Atmos., 115, D17206, doi:10.1029/2009jd013310, 2010.

McComiskey, A., Schwartz, S. E., Schmid, B., Guan, H., Lewis, E. R., Ricchiazzi, P., and Ogren, J. A.: Direct aerosol forcing: Calculation from observables and sensitivities to inputs, J. Geophys. Res.-Atmos., 113, D09202, doi:10.1029/2007JD009170, 2008.

Myhre, G.: Consistency between satellite-derived and modeled estimates of the direct aerosol effect, Science, 325, 187-190, 2009.

Myhre, G., Samset, B. H., Schulz, M., Balkanski, Y., Bauer, S., Berntsen, T. K., Bian, H., Bellouin, N., Chin, M., Diehl, T., Easter, R. C., Feichter, J., Ghan, S. J., Hauglustaine, D., Iversen, T., Kinne, S., Kirkevåg, A., Lamarque, J.-F., Lin, G., Liu, X., Lund, M. T., Luo, G., Ma, X., van Noije, T., Penner, J. E., Rasch, P. J., Ruiz, A., Seland, Ø., Skeie, R. B., Stier, P., Takemura, T., Tsigaridis, K., Wang, P., Wang, Z., Xu, L., Yu, H., Yu, F., Yoon, J.-H., Zhang, K., Zhang, H., and Zhou, C.: Radiative forcing of the direct aerosol effect from AeroCom Phase II simulations, Atmos. Chem. Phys., 13, 1853-1877, doi:10.5194/acp-13-18532013, 2013.
Petters, M. D. and Kreidenweis, S. M.: A single parameter representation of hygroscopic growth and cloud condensation nucleus activity, Atmos. Chem. Phys., 7, 1961-1971, doi:10.5194/acp-71961-2007, 2007.

Ran, L., Zhao, C. S., Xu, W. Y., Lu, X. Q., Han, M., Lin, W. L., Yan, P., Xu, X. B., Deng, Z. Z., Ma, N., Liu, P. F., Yu, J., Liang, W. D., and Chen, L. L.: VOC reactivity and its effect on ozone production during the HaChi summer campaign, Atmos. Chem. Phys., 11, 4657-4667, doi:10.5194/acp-11-4657-2011, 2011.

Redemann, J., Russell, P. B., and Hamill, P.: Dependence of aerosol light absorption and single-scattering albedo on ambient relative humidity for sulfate aerosols with black carbon cores, J. Geophys. Res.-Atmos., 106, 27485-27495, doi:10.1029/2001jd900231, 2001.

Remer, L. A. and Kaufman, Y. J.: Aerosol direct radiative effect at the top of the atmosphere over cloud free ocean derived from four years of MODIS data, Atmos. Chem. Phys., 6, 237-253, doi:10.5194/acp-6-237-2006, 2006.

Ricchiazzi, P., Yang, S., Gautier, C., and Sowle, D.: SBDART: A research and teaching software tool for plane-parallel radiative transfer in the Earth's atmosphere, B. Am. Meteorol. Soc., 79, 2101-2114, 1998.

Seinfeld, J. H. and Pandis, S. N.: Atmospheric chemistry and physics: from air pollution to climate change, John Wiley \& Sons, New York, USA, 701-1118, 2006.

Sena, E. T., Artaxo, P., and Correia, A. L.: Spatial variability of the direct radiative forcing of biomass burning aerosols and the effects of land use change in Amazonia, Atmos. Chem. Phys., 13, 1261-1275, doi:10.5194/acp-13-1261-2013, 2013.

Smirnov, A., Holben, B. N., Eck, T. F., Slutsker, I., Chatenet, B., and Pinker, R. T.: Diurnal variability of aerosol optical depth observed at AERONET (Aerosol Robotic Network) sites, Geophys. Res. Lett., 29, 2115, doi:10.1029/2002g1016305, 2002.

Su, W., Loeb, N. G., Schuster, G. L., Chin, M., and Rose, F. G.: Global all-sky shortwave direct radiative forcing of anthropogenic aerosols from combined satellite observations and GOCART simulations, J. Geophys. Res.-Atmos., 118, 655-669, 2013.

Sun, Y., Zhou, X., Wai, K., Yuan, Q., Xu, Z., Zhou, S., Qi, Q., and Wang, W.: Simultaneous measurement of particulate and gaseous pollutants in an urban city in North China Plain during the heating period: Implication of source contribution, Atmos. Res., 134, 24-34, doi:10.1016/j.atmosres.2013.07.011, 2013.

Tao, J. C., Zhao, C. S., Ma, N., and Liu, P. F.: The impact of aerosol hygroscopic growth on the single-scattering albedo and its application on the $\mathrm{NO}_{2}$ photolysis rate coefficient, Atmos. Chem. Phys., 14, 12055-12067, doi:10.5194/acp-14-12055-2014, 2014.

Wex, H., Neususs, C., Wendisch, M., Stratmann, F., Koziar, C., Keil, A., Wiedensohler, A., and Ebert, M.: Particle scattering, backscattering, and absorption coefficients: An in situ closure and sensitivity study, J. Geophys. Res.-Atmos., 107, 8122, doi:10.1029/2000jd000234, 2002.

Xu, W. Y., Zhao, C. S., Ran, L., Deng, Z. Z., Liu, P. F., Ma, N., Lin, W. L., Xu, X. B., Yan, P., He, X., Yu, J., Liang, W. D., and Chen, L. L.: Characteristics of pollutants and their correlation to meteorological conditions at a suburban site in the North China Plain, Atmos. Chem. Phys., 11, 4353-4369, doi:10.5194/acp-114353-2011, 2011. 
Zhang, Y., Yu, H., Eck, T. F., Smirnov, A., Chin, M., Remer, L. A., Bian, H., Tan, Q., Levy, R., and Holben, B. N.: Aerosol daytime variations over North and South America derived from multiyear AERONET measurements, J. Geophys. Res.-Atmos., 117, D05211, doi:10.1029/2011JD017242, 2012.
Zhao, C., Tie, X., and Lin, Y.: A possible positive feedback of reduction of precipitation and increase in aerosols over eastern central China, Geophys. Res. Lett., 33, L11814, doi:10.1029/2006GL025959, 2006. 